\title{
COMMENTARY
}

\section{Tracheal Ligation and Corticosteroids in Congenital Diaphragmatic Hernia: For Better for Worse?}

\author{
Commentary on the article by Kay et al. on page 495
}

\author{
M. VAN TUYL, M. HÖSGOR, AND D. TIBBOEL \\ Department of Pediatric Surgery, Sophia Children's Hospital, Dr. Molewaterplein 60, 3015 GJ \\ Rotterdam, The Netherlands [M.T., M.H., D.T.] and Lung Biology Research Laboratory, Hospital for Sick \\ Children, Toronto, Canada [M.T.]
}

$\mathrm{C}$ ongenital diaphragmatic hernia $(\mathrm{CDH})$ continues to frustrate clinicians for several reasons: it is not possible to predict accurately the extent of pulmonary hypoplasia in the individual fetus and the postnatal response to treatment modalities such as inhalational nitric oxide (NO) is variable. Moreover, the use of extra corporeal membrane oxygenation (ECMO) carries a high morbidity and sometimes profound long-term sequelae.

Analysis of the literature reveals a myriad of treatment modalities proposed as "solutions" for the problem pulmonary hypoplasia in $\mathrm{CDH}$. They range from termination of pregnancy following prenatal ultrasound to gentle handling of the lung postnatally to diminish iatrogenic damage of the fragile hypoplastic lungs (1). The fetal sheep model of $\mathrm{CDH}$ opened the way to fetal intervention and endoscopic fetoscopic procedures (FETENDO) such as tracheal ligation/occlusion in the human (2-7). Others have studied the basic mechanisms of pulmonary growth in a drug-induced CDH model (the Nitrofen rodent model) with or without the evaluation of additional treatment modalities such as corticosteroids and/or TSH releasing hormone (TRH) (8-14).

The supposed "lung growth" resulting from tracheal ligation is not founded on clean concepts of underlying mechanisms, although a variety of factors has been suggested (15-17).

Intriguing are recent observations from different laboratories of the negative effects of tracheal ligation, in fetal sheep, on type II cell differentiation, as nicely evaluated by Kay et al. in this issue (18). The question of whether we will end up with a combined approach of tracheal ligation/occlusion and maternal betamethasone therapy to rescue type II cell differentiation as optimal treatment of $\mathrm{CDH}$ in humans is therefore still open.

We have to bear in mind that the experiments described in the paper of Kay et al. were not conducted in a CDH model. As a consequence, we can only assume that the response will be the same in the hypoplastic lungs of $\mathrm{CDH}$. However, no research data are available to support this assumption. Other questions are unanswered too, because the authors only as- sessed certain structural features of Type II cell density and markers of mRNA for two surfactant proteins. Whether steroids do more than up-regulate mRNA for the surfactant proteins or enhance function remains controversial. The study by Kay et al. involved no physiologic assessment of lung function, gas exchange or the development of pulmonary hypertension.

Before we apply the results of the experimental approach of Kay et al. in a clinical setting, we have to analyze the arguments for the use of corticosteroids to enhance lung development in prenatally diagnosed $\mathrm{CDH}$, because the few reports on the use of corticosteroids in human $\mathrm{CDH}$ consist of personal communications, individual case reports, and anecdotal small series. However prenatal steroids are used to enhance lung development in premature infants.

A meta-analysis of published studies on prenatal glucocorticoids in threatened premature labor of fetuses without $\mathrm{CDH}$ consistently demonstrated beneficial effects on neonatal outcome for those infants born at 24 to 34 wk of gestation (19). Therefore, the National Institutes of Health consensus recommends antenatal administration of corticosteroids at least for $24 \mathrm{~h}$, but if possible for $48 \mathrm{~h}$, to all fetuses between 24 and 34 wk of gestation at risk of preterm delivery (20). However, as often suggested, it is still contradictory whether lungs of animal and human infants with $\mathrm{CDH}$ are surfactant deficient and morphologic immature like lungs from premature infants with surfactant deficient lung disease that do benefit from antenatal corticosteroid therapy (21). As a consequence it is hard to predict the significance of antenatal corticosteroids for the individual $\mathrm{CDH}$ patient. Moreover, we still do not know the long-term effects of antenatal corticosteroid treatment and there is growing evidence that these drugs may have adverse perinatal and longer term effects $(22,23)$. Profound effects on postnatal alveolar septation have already been documented (24, 25). In this light another important issue, recently raised by Smith et al. (22), is whether to use multiple or single antenatal courses of corticosteroids which is currently in use. 
Considering the high incidence of chronic lung disease in $\mathrm{CDH}$ infants (26) the same concern is warranted for postnatal use of corticosteroids as recently eluded upon by Stark et al. in another group of patients: extremely-low-birth-weight infants (27).

We have to await the result of a recently started randomized controlled trial evaluating the use of betamethasone in prenatally diagnosed $\mathrm{CDH}$, guided by the International $\mathrm{CDH}$ study group (principal investigator: Dr. K. Lally, Houston, U.S.A.)

After demonstration of accelerated lung maturation in premature sheep by Liggins $(28,29)$, several experimental studies in the Nitrofen CDH rodent model as well as in the surgically created sheep model have shown the beneficial effects of antenatal corticosteroid therapy including acceleration of the synthesis and release of surfactant, reduction of alveolar septal thickness, increase in maximum lung volume and compliance, and improvement in the antioxidant defense mechanisms (814). Prenatal use of corticosteroids in the Nitrofen model supposedly changes the pulmonary vascular architecture, although there are no reports of the expression of the glucocorticoid receptor in small pulmonary arteries. In contrast, expression of the thyroid hormone receptor has been described (30). The administration of glucocorticoids and TRH to Nitrofentreated pregnant rats increased di-saturated phosphatidylcholine levels in the fetal offspring, reduced lung glycogen levels and significantly improved lung compliance and morphology (8-11). In addition, in our CDH rat model the combination of dexamethasone and TRH treatment of pregnant rats did not affect survival during ventilation in the pups and decreased glutathione reductase (14). We, therefore, concluded that antenatal administration of dexamethasone as a monotherapy would offer better prospects for randomized trials in prenatally diagnosed children with $\mathrm{CDH}$ than would the combination of dexamethasone and TRH.

\section{Mechanisms of Glucocorticoid Action}

During fetal and postnatal development, glucocorticoids function as signaling molecules to modulate the orderly sequence of differentiation in most tissues. From midgestation onwards, the fetus is exposed to increasing levels of cortisol of primarily fetal origin. Many studies, in humans as well as in animals, have provided strong evidence that the administration of glucocorticoids to the immature fetus accelerates lung maturation. Even "physiologic stressors." such as infection and premature rupture of the membranes, have been shown to accelerate fetal lung maturation, indicating that endogenous fetal glucocorticoids are instrumental in the normal course of lung maturation too. Endogenous hormones, however, do not initiate alveolar epithelial maturation, but are only involved in the modulation of genes responsible for surfactant production (for review see ref. 31).

Corticosteroids are known to induce several components of surfactant and to increase saturated phosphatidylcholine by stimulating key enzymes involved in phospholipid synthesis, such as fatty acid synthetase, choline phosphate cytidylyltransferase, and lysophosphatidylcholine acyl CoA acyl transferase. In addition, they stimulate lamellar body development in type II cells, and increase both tissue and alveolar content of surfactant (32). Finally, they also increase levels of the surfactant-associated proteins A, B, C, and D. In addition to these positive effects on surfactant production, glucocorticoids also stimulate antioxidant enzyme activity (33). Although still not completely defined, some of these effects appear to result largely from increased production of fibroblast-pneumonocyte factor by the fetal lung fibroblasts (34).

In contrast to these positive effects of corticosteroids, a variety of negative effects have been documented in the literature. In cultured lymphocytes, glucocorticoids caused apoptosis and an arrest in the G1 phase of the cell cycle thereby affecting proliferation which may finally lead to a reduction in cell number (35).

Also, prenatal dexamethasone treatment reduced overall DNA, but not the collagen content in lung tissue of neonatal rats (36). Moreover, a recent study showed that prenatal administration of dexamethasone to premature rats exposed to prolonged hyperoxia resulted in increased fibrosis in the dexamethasone treated lungs compared with the lungs from untreated animals (37).

In embryonic rat lung studies, corticosteroid treatment causes distorted branching, tubular dilatation, suppression of lung growth and epithelial cell proliferation, attenuation of mesenchymal tissue and compression of mesenchyme between adjacent epithelial tubules which represent the features of both distorted and accelerated maturation $(38,39)$.

\section{Glucocorticoid-Receptor Interaction}

Glucocorticoids exert their effects via a nuclear receptor of the steroid hormone receptor superfamily. This superfamily includes a number of ligand-responsive transcriptional enhanced proteins, including the glucocorticoid and thyroid hormone receptors. All members of the family share a highly conserved modular structure, with discrete functional domains for hormone binding, DNA binding, and transactivation (40). Concomitant with a rise in glucocorticoid plasma levels near term, enhancement of glucocorticoid receptor gene expression has been shown by Sweezy et al. in the fetal rat (41). Autoradiographic localization studies demonstrated increased glucocorticoid receptor gene expression in the mesenchyme, and more specifically in those mesenchymal cells adjacent to the terminal saccular epithelium (the cell population responsible for fibroblast-pneumonocyte factor production) $(42,43)$. To enhance our understanding of the potential effects of corticosteroids on the hypoplastic lung, we studied the glucocorticoid (GC)-receptor in hypoplastic CDH rat lungs and age-matched controls. No significant differences were observed in the tissue distribution or time of appearance of the GC-receptor under these experimental conditions (30).

\section{Modulation of Pulmonary Growth in CDH}

Findings presented at the 16th annual ECMO meeting in Keystone (March 2000) by investigators from Boston (J. Wilson, J. Schnitzer) and Liverpool (P. Losty) made it likely that members of the fibroblast growth factor family play important roles in an organotypic culture system of hypoplastic lungs in Nitrofen-induced CDH. During that same meeting Ch. Stolar 
and colleagues advocated a pivotal impact of other well known growth factors, such as vascular endothelial derived growth factor (VEGF), on lung growth following tracheal ligation in the sheep CDH model as well as in an organotypic culture system including both the embryonic rat heart and lung buds. This is especially intriguing because human $\mathrm{CDH}$ lungs showed abnormal expression of VEGF, even in the endothelium of pulmonary arteries less than $75 \mu \mathrm{m}$ (44).

In the light of the international corticosteroid treatment protocol of prenatally diagnosed $\mathrm{CDH}$, including over 300 patients, and the National Institutes of Health sponsored tracheal ligation/occlusion study of prenatally diagnosed $\mathrm{CDH}$ patients with the highest risk ("liver up" patients), we must bear in mind that our knowledge of the optimal way to modulate prenatal pulmonary growth and differentiation is far from complete.

Although corticosteroids are known to induce apoptosis, they exert intriguing effects, not yet evaluated in humans, on VEGF expression and platelet-derived growth factor (PDGF), and on the PDGF-A receptor and pulmonary fibroblasts (45-47).

The presumed negative effects of tracheal ligation on type II cell differentiation in experimental $\mathrm{CDH}$ models are reason to carefully evaluate the use of corticosteroids in human cases. Not only the overall outcome should be assessed but also the more fundamental cell-biologic changes occurring during the transition from the saccular phase of pulmonary development to the alveolar phase, which takes place late in gestation in humans. The application of new technology such as the use of micro-arrays will help us to understand pulmonary development at the molecular level. The time dependent expression of a number of genes relevant for the progression in lung development in general $(48,49)$ should be taken into account, both in spontaneous as well as in experimental induced $\mathrm{CDH}$. In this way we will be able to pinpoint the exact mechanisms resulting into pulmonary hypoplasia in $\mathrm{CDH}$ as well as the effect of modulating "agents" such as corticosteroids. We cannot run the risk that tracheal ligation with or without corticosteroids although "again" suggested as magic bullets for the improvement of the survival rate in newborns with $\mathrm{CDH}$, turns out to be a new chapter in the book of unanswered questions in congenital diaphragmatic hernia.

\section{REFERENCES}

1. IJsselstijn H, Tibboel D 1998 The lungs in congenital diaphragmatic hernia: do we understand? Pediatr Pulmonol 26:204-218

2. Hashim E, Laberge JM, Chen MF, Quillen EW Jr 1995 Reversible tracheal obstruction in the fetal sheep: effects on tracheal fluid pressure and lung growth. J Pediatr Surg 30:1172-1177

3. Wilson JM, DiFiore JW, Peters CA 1993 Experimental fetal tracheal ligation prevents the pulmonary hypoplasia associated with fetal nephrectomy: possible application for congenital diaphragmatic hernia. J Pediatr Surg 28:1433-1440

4. Piedboeuf B, Laberge JM, Ghitulescu G, Gamache M, Petrov P, Belanger S, Chen MF, Hashim E, Possmayer F 1997 Deleterious effect of tracheal obstruction on type II pneumocytes in fetal sheep. Pediatr Res 41:473-479

5. Benachi A, Chailley-Heu B, Delezoide AL, Dommergues M, Brunelle F, Dumez Y, Bourbon JR 1998 Lung growth and maturation after tracheal occlusion in diaphragmatic hernia. Am J Respir Crit Care Med 157:921-927

6. Flageole H, Evrard VA, Piedboeuf B, Laberge JM, Lerut TE, Deprest JA 1998 The plug-unplug sequence: an important step to achieve type II pneumocyte maturation in the fetal lamb model. J Pediatr Surg 33:299-303

7. Harrison MR, Mychaliska GB, Albanese CT, Jennings RW, Farrell JA, Hawgood S, Sandberg P, Levine AH, Lobo E, Filly RA 1998 Correction of congenital diaphrag- matic hernia in utero IX: fetuses with poor prognosis (liver herniation and low lung-to-head ratio) can be saved by fetoscopic temporary tracheal occlusion. J Pediatr Surg 33:1017-1023

8. Suen HC, Bloch KD, Donahoe PK 1994 Antenatal glucocorticoid corrects pulmonary immaturity in experimentally induced congenital diaphragmatic hernia in rats. Pediatr Res 35:523-529

9. Suen HC, Losty PD, Donahoe PK, Schnitzer JJ 1994 Combined antenatal thyrotropinreleasing hormone and low-dose glucocorticoid therapy improves the pulmonary biochemical immaturity in congenital diaphragmatic hernia. J Pediatr Surg 29:359363

10. Losty PD, Suen HC, Manganaro TF, Donahoe PK, Schnitzer JJ 1995 Prenatal hormonal therapy improves pulmonary compliance in the nitrofen-induced $\mathrm{CDH}$ rat model. J Pediatr Surg 30:420-426

11. Losty PD, Pacheco BA, Manganaro TF, Donahoe PK, Jones RC, Schnitzer JJ 1996 Prenatal hormonal therapy improves pulmonary morphology in rats with congenital diaphragmatic hernia. J Surg Res 65:42-52

12. Schnitzer JJ, Hedrick HL, Pacheco BA, Losty PD, Ryan DP, Doody DP, Donahoe PK 1996 Prenatal glucocorticoid therapy reverses pulmonary immaturity in congenital diaphragmatic hernia in fetal sheep. Ann Surg 224:430-439

13. Hedrick HL, Kaban JM, Pacheco BA, Losty PD, Doody DP, Ryan DP, Manganaro TF, Donahoe PK, Schnitzer JJ 1997 Prenatal glucocorticoids improve pulmonary morphometrics in fetal sheep with congenital diaphragmatic hernia. J Pediatr Surg 32:217-222

14. IJsselstijn H, Pacheco BA, Albert A, Sluiter W, Donahoe PK, De Jongste JC, Schnitzer JJ, Tibboel D 1997 Prenatal hormones alter antioxidant enzymes and lung histology in rats with congenital diaphragmatic hernia. Am J Physiol 272:L1059L1065

15. Kitano Y, Yang EY, von Allmen D, Quinn TM, Adzick NS, Flake AW 1998 Tracheal occlusion in the fetal rat: a new experimental model for the study of accelerated lung growth. J Pediatr Surg 33:1741-1744

16. Kitano Y, Adzick NS 1999 New developments in fetal lung surgery. Curr Opin Pulm Med 5:383-389

17. Kitano Y, Davies P, von Allmen D, Adzick NS, Flake AW 1999 Fetal tracheal occlusion in the rat model of nitrofen-induced congenital diaphragmatic hernia. J Appl Physiol 87:769-775

18. Kay S, Laberge J-M, Flageole H, Richardson S, Belanger S, Piedboeuf B 2001 Use of antenatal steroids to counteract the negative effects of tracheal occlusion in the fetal lamb model. Pediatr Res 50:495-501

19. Crowley PA 1995 Antenatal corticosteroid therapy: a meta-analysis of the randomized trials, 1972 to 1994. Am J Obstet Gynecol 173:322-335

20. Editorial 1995 Effect of corticosteroids for fetal maturation on perinatal outcomes. NIH Consensus Development Panel on the Effect of Corticosteroids for Fetal Maturation on Perinatal Outcomes. JAMA 273:413-418

21. IJsselstijn H, Zimmermann LJ, Bunt JE, de Jongste JC, Tibboel D 1998 Prospective evaluation of surfactant composition in bronchoalveolar lavage fluid of infants with congenital diaphragmatic hernia and of age-matched controls. Crit Care Med 26:573580

22. Smith GN, Kingdom JC, Penning DH, Matthews SG 2000 Antenatal corticosteroids: is more better? Lancet 355:251-252

23. Kay HH, Bird IM, Coe CL, Dudley DJ 2000 Antenatal steroid treatment and adverse fetal effects: what is the evidence? J Soc Gynecol Invest 7:269-278

24. Tschanz SA, Burri PH 1997 Postnatal lung development and its impairment by glucocorticoids. Pediatr Pulmonol Suppl 16:247-249

25. Ikegami M, Jobe AH, Newnham J, Polk DH, Willet KE, Sly P 1997 Repetitive prenatal glucocorticoids improve lung function and decrease growth in preterm lambs. Am J Respir Crit Care Med 156:178-184

26. Bos AP, Hussain SM, Hazebroek FW, Tibboel D, Meradji M, Molenaar JC 1993 Radiographic evidence of bronchopulmonary dysplasia in high-risk congenital diaphragmatic hernia survivors. Pediatr Pulmonol 15:231-234

27. Stark AR, Carlo WA, Tyson JE, Papile LA, Wright LL, Shankaran S, Donovan EF, Oh W, Bauer CR, Saha S, Poole WK, Stoll BJ; National Institute of Child Health and Human Development Neonatal Research Network 2001 Adverse effects of early dexamethasone treatment in extremely-low-birth-weight infants. N Engl J Med 344:95-101

28. Liggins GC 1969 Premature delivery of foetal lambs infused with glucocorticoids. J Endocrinol 45:515-523

29. Liggins GC 1968 Premature parturition after infusion of corticotrophin or cortisol into foetal lambs. J Endocrinol 42:323-329

30. Keijzer R, Blommaart PJE, Lamers WH, Tibboel D 1998 An ontogenic study of steroid hormone receptor expression in lungs of congenital diaphragmatic hernia rats and age matched controls. Am J Respir Crit Care Med 157:A174

31. Ballard PL 1987 Glucocorticoid regulation of lung maturation. Mead Johnson Symp Perinat Dev Med 30:22-27

32. Ballard PL 1989 Hormonal regulation of pulmonary surfactant. Endocr Rev 10:165181

33. Walther FJ, Ikegami M, Warburton D, Polk DH 1991 Corticosteroids, thyrotropinreleasing hormone, and antioxidant enzymes in preterm lamb lungs. Pediatr Res 30:518-521

34. Smith BT, Post M 1989 Fibroblast-pneumonocyte factor. Am J Physiol 257:L174L178

35. King KL, Cidlowski JA 1998 Cell cycle regulation and apoptosis. Annu Rev Physiol 60:601-617

36. Schellenberg JC, Liggins GC, Stewart AW 1987 Growth, elastin concentration, and collagen concentration of perinatal rat lung: effects of dexamethasone. Pediatr Res 21:603-607 
37. Chen Y, Martinez MA, Frank L 1997 Prenatal dexamethasone administration to premature rats exposed to prolonged hyperoxia: a new rat model of pulmonary fibrosis (bronchopulmonary dysplasia). J Pediatr 130:409-416

38. Oshika E, Liu S, Singh G, Michalopoulos GK, Shinozuka H, Katyal SL 1998 Antagonistic effects of dexamethasone and retinoic acid on rat lung morphogenesis. Pediatr Res 43:315-324

39. Oshika E, Liu S, Ung LP, Singh G, Shinozuka H, Michalopoulos GK, Katyal SL 1998 Glucocorticoid-induced effects on pattern formation and epithelial cell differentiation in early embryonic rat lungs. Pediatr Res 43:305-314

40. Evans RM 1988 The steroid and thyroid hormone receptor superfamily. Science 240:889-895

41. Sweezey NB, Ghibu F, Gagnon S, Schotman E, Hamid Q 1998 Glucocorticoid receptor mRNA and protein in fetal rat lung in vivo: modulation by glucocorticoid and androgen. Am J Physiol 275:L103-L109

42. Beer DG, Butley MS, Cunha GR, Malkinson AM 1984 Autoradiographic localization of specific $[3 \mathrm{H}]$ dexamethasone binding in fetal lung. Dev Biol 105:351-364

43. Caniggia I, Tseu I, Han RN, Smith BT, Tanswell K, Post M 1991 Spatial and temporal differences in fibroblast behavior in fetal rat lung. Am J Physiol 261:L424L433
44. Shehata SM, Mooi WJ, Okazaki T, El-Banna I, Sharma HS, Tibboel D 1999 Enhanced expression of vascular endothelial growth factor in lungs of newborn infants with congenital diaphragmatic hernia and pulmonary hypertension. Thorax 54:427-431

45. Nauck M, Roth M, Tamm M, Eickelberg O, Wieland H, Stulz P, Perruchoud AP 1997 Induction of vascular endothelial growth factor by platelet-activating factor and platelet-derived growth factor is downregulated by corticosteroids. Am J Respir Cell Mol Biol 16:398-406

46. Warshamana GS, Martinez S, Lasky JA, Corti M, Brody AR 1998 Dexamethasone activates expression of the PDGF-alpha receptor and induces lung fibroblast proliferation. Am J Physiol 274:L499-L507

47. Bruce MC, Honaker CE, Cross RJ 1999 Lung fibroblasts undergo apoptosis following alveolarization. Am J Respir Cell Mol Biol 20:228-236

48. Sekine K, Ohuchi H, Fujiwara M, Yamasaki M, Yoshizawa T, Sato T, Yagishita N, Matsui D, Koga Y, Itoh N, Kato S 1999 FGF10 is essential for limb and lung formation. Nat Genet 21:138-141

49. Bellusci S, Furuta Y, Rush MG, Henderson R, Winnier G, Hogan BL 1997 Involvement of Sonic Hedgehog (Shh) in mouse embryonic lung growth and morphogenesis. Development 124:53-63 